\title{
Sentiment Analysis of Sarcasm in Spoken Language
}

\author{
Yuli Angraini \\ English Education Department \\ University of Riau Kepulauan \\ angraini_yuli@yahoo.com
}

\begin{abstract}
The objectives of the research were (1) to find out how often people used sentiment sarcasm in spoken language,(2) to know the effect of the use of sentiment sarcasm in people's life and (3) to find out the reason why people used sentiments sarcasm when they talked to other people. The subject of the research was 26 random person consisted of native speakers and also non native speakers, specifically in public scope.The method of the research was qualitative research in the form of non participant observation. That data was collected by using interview done by the fourth semester students of Batam Center in their final semester in Speaking IV subject. All data were recorded and analyzed by using percentage. Based on 26 person's interview, it was found that (1) 65\% people often used sentiment sarcasm to other people when they wanted to be nasty and thought those people they talked too were deserved to get sentiments sarcasm from them; $25 \%$ people did not like to use it to other people as it could hurt and put them into lowest position;and 10\% people never used sentiment sarcasm at all as they chose to say directly about their intention to other people; (2) Most of people who used sentiment sarcasm to other people got the lesson of life as they had to learn to respect other people and use sentiment sarcasm in some cases only not in all situation as it brought bad effect and pain to other people who felt the impact of sentiment sarcasm; (3)There were many reasons behind sentiment sarcasm they used, but there were three most striking reason were that they wanted to give lesson to other people so they could respect people whom they talked too; to protect other's feeling from getting hurt after revealing the truth; and to trigger their emotion that could motivate them to be a better person in life.
\end{abstract}

\section{INTRODUCTION}

The power of word. It is undeniable that the power of word can bring some impact to some people especially in its interpretation in their mind. Even the simple word like "eat" can be transmited into different ways. For example: "You can eat my meal easily." In common people, that word meant he or she could just eat that meal without being worry of something while another way it could be interpreted that person made sarcasm as he or she knew that person was greedy that could swallow anything without asking for permission or realizing she or he already got the same portion. If that situation brought into face to face situation then it would have no difficulty to recognize the literal meaning behind it by using intonation and gesture. However, if not then it will depend on people’s imagination. 
Another example of word that can be interpreted differently by other people, it will be shown from text message below:

Vova: "Hello, Yesha said that now big discount in Flamming. One ticket for one seat costs 4.7 millions. If your job is almost complete then maybe it is wise to book tickets? What do you think? Nice weekends!

From that sentences, it seemed nothing was wrong and it was just about asking for a better choice. Nothing else. However those simple sentences could bring a disaster for some people who thought differently as the following:

Ann: "Yesha....The cheaper seat information that you gave, try to be wiser a bit. Not only cheaper, but look on how long we must wait....how many times I must call the committee there.....all of those must be counted. That seat information you shared to Vova, then Vova shared to me, but you just looked the cheaper price without any other consideration. So, please be wise a bit.

Based on that sentences, it is clear that there is an unexpected reaction and the offensive feeling in a repeated word "Wise". Ann emphasized the word "wise" in the form of sarcasm to reply Vova message through Yesha. For people who cannot recognize that it is sarcasm then it will be difficult for them to understand what other people feel. Soooner or later it will lead and put them into difficult and uncomfortable situation as they do not know what kind of people they face.

Referring to that, there are three types of people in this life, they are (1) The honest one; (2) A true liar and the last one is (3) A white liar. The first type is people who always tell the truth no matter how it can hurt other people's feeling. In their concept of mind, the true must be revealed otherwise their own feeling can be exhausted to hold a lie like in this dialogue below:

Natasha : "Honey, I need you buy me those two shoes.

Sasha : What for? I think one is enough for you.

Natasha : Are you kidding me? I really need that. My job location was too far from my home and I must walk by using sneaker shoes and change it into high heels as I really look like a foolish woman if I wear sneaker in my office. People will stare at me and wonder that something is wrong with my mind as I am not a student anymore and I am in a formal situation in my office. In that case, I need two 
shoes. It can save money as my shoes will never be broken anymore.

Sasha : You are too greedy! I cannot afford to buy you two shoes. One shoes is enough for you. Choose the strongest one that you can wear both when you walk to your office and in your office.

Natasha : (crying...)

From the above dialogue, it is clear that both of them are honest people. Sasha said what he thought right that time. He used his logical mind that Natasha is better to choose one shoes that can fit for all occassion apart from his financial condition. One thing that Natasaha might not care of. On the other hand, Natasha made her own thought by giving her opinion to her boyfriend if she chose to buy sneaker and wore it also in her office then her coworkers could insult her dignity as not many of them wore sneaker in their office. It would put her in embarrassing and awkward situation. Both of them were offended because they expressed what they thought true though they were not totally wrong at all as they had an alibi.

The second type of people is a true liar. This type is common in life. They can lie even when they sleep. Their victims usually people who do not appreciate themselves and always in a positive mind. Surely it is good but the positive mind people who lack of awareness of situation then the liar predator can swallow them such as in this situation below:

Vanya: I am starving. I have no money to buy food (Crying.....)

Sasha : Don’t worry my love, I will transfer you the money today. Buy meat, vegetables, fruit, anything.... You will not starve anymore. Eat healthy food with that money.

Vanya: Thank you my love. I always can count on you everytime I get problem.

Sasha : Don’t say thanks my love. I love you.

Vanya: (A phone was closed...she smiled and laughed).

A contradictory with the first type is people who think that a lie is necessary. They often make justification to themselves if all people lie then why they cannot do the same 
thing, so nothing is wrong with that. They covered one lie with another lie and consciously or not those lies already united in their daily life.

Almost the same genre with the second type is people who believe that a little lie can protect other people's feeling from getting hurt. It is called a white liar. They often can pretend that everything is ok while it is not as the following :

Tanya: (Translating something to Sergey through talking...)

Sergey: (Smiling and typing something)

Tanya : Why did you smile? What did you type? We were talking then with who did you type?

Sergey: I typed the translation and I smiled to Google.

Tanya : What for? I already translated you and my translation was not funny. Honestly to whom did you talk? I will not be angry.

Sergey: Ok...Ok...It was my friend from college texted me.

Tanya : That woman? Your best friend from college? No wonder you smiled. You lied to me!

Sergey: I knew it. That was why I lied to you because I knew you would be jealous to her and to all of my friend. I lied to you because you always thought bad of me.

Tanya : I have no words anymore for you.

In that situation, that man tried to hide his friend because he knew his girlfriend's character. He did not want to make fight so he did a white lie that he thought it could save him from fight with his girlfriend. However, it did not work at all. It led to a clumsy situation as his girlfriend felt her boyfriend had already betrayed her somehow and lie is a lie no matter what the reason is.

Some people can stand with such a unique situation, but others no. When someone tries to attack someone else's dignity, patience and fear, she or he tended to use sarcasm to show what they feel to that people as below:

Bella : What is he doing?

Sheen : He is still planning. 
Bella : What?? Seriously?!! We are getting closer to the deadline! We even can gulp our steak just like that without even chew it but he is still planning?

Oh God! I really wanna shot my head now.

Sheen : We still have time, just try not think about that or you will be crazy. Just pray for best.

Bella : I wish.

In that dialogue, Bella used a sarcasm "We even can gulp our steak just like that without even chew it . I really wanna shot my head now”, to express her anger of that man whom supposed to finish their job on time as the schedule almost over. It may be categorized as soft sarcam as Bella did not use rough sarcasm and the tone she used she referred to her own disappointment as that man's failure also her failure too, but it will be a different case if she chose a very sensitive sarcasm that intended to hurt that man's feeling. Maybe the result will be more complicated as all people are geting involved there.

Thus, based on that, the writer wanted to find out the answers in the form of descriptive qualitative research entitled "Sentiment Analysis of Sarcasm in Spoken Language.” The objectives of the research were (1) to find out how often people used sentiment sarcasm in spoken language,(2) to know the effect of the use of sentiment sarcasm in people's life and (3) to find out the reason why people used sentiments sarcasm when they talked to other people.

\section{IRONY}

Abrams and Harpham (2009:165-168) said that in most of the modern critical uses the term "irony," there remains the root sense of dissembling, or of hiding what is actually the case; not, however, in order to deceive, but to achieve special rhetorical or artistic effects. There are five types of Irony. They are:

\section{Verbal Irony}

It is a statement in which the meaning that a speaker implies differs sharply from the meaning that is ostensibly expressed. The ironic statement usually involves the explicit expression of one attitude or evaluation, but with indications in the overall speech-situation that the speaker intends a very different, and often opposite, attitude or evaluation. 


\section{Structural Irony}

It depends on a knowledge of the author's ironic intention, whiich is shared by the reader but is not intended by the fictional speaker.

\section{Stable Irony}

The speaker or author makes available to the reader an assertion or position which, whether explicit or implied, serves as a firm ground for ironically qualifying or subverting the surface meaning.

\section{Unstable Irony}

It offers no fixed standpoint which is not itself undercut by further ironies.

\section{Sarcasm}

It used as an equivalent for all forms of irony, but it is far more useful to restrict it only to the crude and taunting use of apparent praise for dispraise: “Oh, you're God's great gift to women, you are!" The difference in application of the two terms is indicate by the difference in their etymologies; whereas "irony" derives from “eiron,” a "dissembler," "sarcasm” derives from the Greek verb "sarkazein,” "to tear flesh.” An added clue to sarcasm is the exaggerated inflection of the speaker's voice.

\section{PERSONA, TONE, AND VOICE}

\section{Persona}

It is often appliedto the first-person speaker who tells the story in a narrative poem or novel, or whose voice people hear in a lyric poem.

\section{Tone}

Tone is as the expression of a literary speaker's attitude to the listener. The way people speak reveals, by subtle clues, the conception of, and attitude toward, the things people are talking about, their personal relationship to their auditor, and also their assumption about the social level, intelligence, and sensitivity of that auditor. The tone of a speech can be described as critical or approving, formal or intimate, outspoken or reticent, solemn or playful, arrogant or prayerful, angry or loving, serious or ironic, condescending or obsequious, and so on through numberless possible nuances of relationship and attitude both to object and auditor. 


\section{Voice}

It distinguished between the author's "false voice" and his or her "true voice" is to discover oneself. That the sense of a convincing authorial voice and presence, whose values, beliefs, and moral vision serve implicitly as controlling forces throughout a work, helps to sway the reader to yield the imaginative consent without which a poem or novel would remain an elaborate verbal game.

\section{CONTEXT, SITUATION AND SOCIETY}

Language users are not highly specialized conversationalists but also experienced cognitive experts. Without their constantly updated context models of the current communicative situation, as well as the relevantly activated situation models of what is being talked about, the participants would not be able to understand each other. Most of what goes on in talk is thus invisible, and the well-known ethnomethodological notion of “observability” can thus hardly be taken literally (Dijk, 2009:102).

\section{EFECTIVE LANGUAGE}

There are some rules in language that make communication is more effective to avoid people from getting misunderstood and leading to inevitable chaos. Luntz (2008: 04-26) proposed ten rules of successful communication. They are:

\section{Simplicity: Use Small Words}

Using a long word when a short one would suffice tends to raise suspicions.

\section{Brevity: Use Short Sentences}

Be as brief as possible. Never usea sentence when a phrase will do and never use four words when three can say just as much.

\section{Credibility as Important as Philosophy}

Tell people who you are or what you do. In a simple sentence: Say what you mean and mean what you say.

\section{Consistency Matters}

Finding a good message and then sticking with it takes extraordinary discipline, but it pays off tenfold in the end. 


\section{Novelty: Offer Something New}

There's a simple test to determine whether or not your message has met this rule. If it generates an "I didn't know that” response, you have succeeded.

\section{Sound and Texture Matter}

The sounds and texture of language should be just as memorable as the words themselves.

\section{Speak Aspirationally}

Messages need to say what peoplewant to hear.

\section{Visualize}

Paint a vivid picture.

\section{Ask a Question}

The rhetorical question remains one of the most powerful but underutilized communication tools.

\section{Provide Context and Explain Relevance}

Without context, you cannot establish a message's value, its impact, or most importantly, its relevance.

\section{METHODOLOGY}

The method of the research was qualitative research in the form of non participant observation. Qualitative research is about immersing oneself in a scene and trying to make sense of it-whether at a company meeting, in a community festival, or during interview (Tracy, 2013: 03). Non-participant observation involves observing participants without actively participating. This option is used to understand a phenomenon by entering the community or social system involved, while staying separate from the activities being observed (Liu, 2010:610-612). That data was collected by using interview done by the fourth semester students of Batam Center in their final semester in Speaking IV subject. 


\section{RESULTS}

\section{Data 1:}

Interviewer 1 (Rizky Uswatun) ; Interviewee (Albert Hutajuru \& Mr. Manov van den Nutt)

R: Did you ever hear sarcasm in society?

A: Of course. Sometimes when I hate someone I used sarcasm for bullying them.

R: Why did you do that?

A: I dunno. I think to put someone in down but actually I don't recognize when I used sarcasm.

R: How do you think about sarcasm?

M: Sometimes sarcasm can be used in fun way. Make a little sense of joke but the most of the time it was used in a negative way and if it is used negative I don't like because people are not honest. They did try to make people down. That's not much if it's in fun way.

R: Did you ever use sarcasm?

M: Of course. Everybody used it but only I try to minimal.

R: Can you tell me the example of sarcasm that you used? Why do you use it and what's the reason? Is it useful? Can you give advice for me and my friend about sarcasm?

M: Actually I use for fun. Small example sometimes my wife a little bit older and get a little bit grey hair. You knew when women had a little bit grey hair they uh..uh..uh...then I said this like, “you get a little old, huh? No. Honestly, I don’t like. Personally I can’t tell about my opinion to other people about it. Advice? Usually in a fun way but don't do in a very serious way that could make somebody down that make somebody really "smal".

\section{Data 2:}

\section{Interviewer 1 (Wiwien Muslyana) ; Interviewee (Mr. Douglas)}

W: What you think about sarcasm, is it useful and have you ever used it?

D: I want to try to give example. Sarcasm. You say one word but you mean the opposite. Let' say you talk about someone who not really run well then you said "You really ran fast". Somebody tells you something that lacking of interest but you really don't feel interesting and you said in Australian slang , “ Oh big whoop!” ...that sarcasm. Sometimes it's brings funny or joke for somebody but usually it's nasty. It's really not good and it's not polite but it's not their kind of conversation usually like that but it can be different for somebody used not a native speaker because they knew what they realized. People is being...that you tried to say something that sarcastic. I'll give you an example. In Australia, people do have a good friend. They often referred to those friends in normals. I'll come up to old friends inside "Get out you all bastards!” What they really mean "I'm really happy to see you good friends". That is not quite sarcasm but that's quite like sarcasm. It means you referred to somebbody very disparaging like that. It's a custom but if you're let say an Australian goes to America while they don't have a tradition like that and they don't have style joking like that. We an Australian goes to 
America while they don't have tradition like that. They have tradition in New Zealand, in UK maybe but you guys in America but you don't have joking style like that we call it stirring make stirring the pot. So they go to America I said "Get out you all bastard!" The American said "What I have done?", so it can be different for somebody who not familiar with the language not native speaker. I used sarcasm sometimes when I want to be nasty to somebody when I want to be bragging about something maybe I would be sarcastic in describing it because that can be strong way be being critical.

\section{Data 3:}

\section{Interviewer 1 (Ika Natalia) ; Interviewee (Glassie)}

I: Tell us what you think about sarcasm.

G: Ok. Sarcasm if for others is negative and for others is positive. For others is the highest form of way is the way you end...you respond for others kinds of stupid for others is not. It means knowledge for them. If you are sarcastic for them you are intelligent for others you're kind of stupid if you are so sarcastic. But for me because sarcasm I'm also sarcastic. It's the way of living, it's the way of dealing with people. It depends on the people I'm dealing with. If I'm dealing with my friend, so I can be sarcastic to them but if I'm dealing with those people higher than me I should respect those people too. I don't do such a thing to them.

I: So what we say, is that sarcasm depend on the age?

G: Yes, it does because age...comes with your...hmm..experience...you know when you're getting older you lead many people and you will learn many things from them and you will have of course experience. So being sarcastic is sometimes we or you have to think first of the person you are talking to. If that person are younger than you and if that person they act to the person some kind of happy-go-lucky or the person who does not care about your word but ...if that person kind of the person that has his own mind or speak has own mind so you have to be aware of your words too.

I: So can yo tell some examples have you ever being a victim of sarcasm or have you ever used that for the other?

G: When I was in college, I noticed my attitude being sarcastic when I was in SMP 2. It was biology class. It was the time when my teacher had her 30 yet...I can still remember this time...birthday and she said to us, "Hey class it's my birthday and I'm getting older and I shouted in front of my classmate and shout that "You already a grandmother...grandmother" , and that many people laughed because they knew me but my teacher got mad until she went out. She was absent for three days. My grade I'm not proud of this but I took the exam and I got one mistake in our exam but my grade is very low because of my attitude. That was the first thing I said to myself I would never did that again but It happened when I was in college that my History teacher asked me about time and I said it's still afternoon because the rule says if it is 05.30 then you say it's 05.30 the afternoon. For me it's just sarcastic with joke but he got mad at me and he said to me I have to be aware of my tongue and I never repeated anymore because I was afraid of.

I: So how about the victiom of sarcasm of the other?

G: Being a victiom of sarcasm from the other. Yes when I was in college I was the victiom of it. I was talking with my friends and another person came and he dealth with me with some jokes and then my friend said "Whyyou are joking with Glassie with that word?", 
and she said Glassie can accept that because she was one of sarcastic. She can understand me because we are sarcastic too. I said I'm not your friend. I'm sarcastic but I'm not your friend. So something like that. I got mad of it.

I: So for others, it was a normal thing?

G: Yes, because they can see me as a sarcastic and they can say to themselves "Oh I can play joke with Glassie because she's also sarcastic and she can understand.

I: So, my last question is what is your point to be young generation about how you dealt with sarcastic in a positive way?

G: You don't have to be quite but just show respect. You can be sarcastic in a right place and the right time but you can't be sarcastic in all situation of life. For example: In your family if your mom was angry with you, why would you speak sarcastically after her, right? So something like that. For me, if my students will sarcastically answer me back, I would totally be angry because it's rule basic.

\section{DISCUSSION}

Based on 26 person's interview, it was found that (1) 65\% people often used sentiment sarcasm to other people when they wanted to be nasty and thought those people they talked too were deserved to get sentiments sarcasm from them; $25 \%$ people did not like to use it to other people as it could hurt and put them into lowest position;and $10 \%$ people never used sentiment sarcasm at all as they chose to say directly about their intention to other people.; (2) Most of people who used sentiment sarcasm to other people got the lesson of life as they had to learn to respect other people and use sentiment sarcasm in some cases only not in all situation as it brought bad effect and pain to other people who felt the impact of sentiment sarcasm; (3)There were many reasons behind sentiment sarcasm they used, but there were three most striking reason were that they wanted to give lesson to other people so they could respect people whom they talked too; to protect other's feeling from getting hurt after revealing the truth; and to trigger their emotion that could motivate them to be a better person in life.

\section{REFERENCES}

Abrams, M.H. and Geoffrey Galt Harpham. (2009). A glossary of literary terms, Ninth Edition. Wadsworth Cengange Learning. Retrieved from: http://www.jasabiza.ir/file/file13926700722.pdf.

A, Teun van Dijk. (2009). Society and discourse: How social contexts influence text and talk. New York: Cambridge University Press. 
Liu, F., \& Maitlis, S. (2010). Nonparticipant observation. In Albert J. Mills, G. Durepos, \& E. Wiebe (Eds.), Encyclopedia of Case Study Research. (pp. 610-612). Thousand Oaks, CA: SAGE Publications. Retrieved from: http://srmo.sagepub.com/view/encyc-of-casestudy-research/n229.xml.

Luntz, DR. Frank. (2008). Words that work: It's not what you say, it's what people hear. New York: Hyperion Ebook. Retrieved from: http://www.mohamedrabeea.com/books/book1_10476.pdf.

Tracy, Sarah J. (2013). Qualitative research methods. Wiley-Blackwell: A John Wiley \& Sons, Ltd., Publication. 